\title{
Adenosquamous carcinoma of the lung
}

This article was published in the following Dove Press journal:

OncoTargets and Therapy

\author{
Chenghui $\mathrm{Li}^{1,2}$ \\ Hongyang $\mathrm{Lu}^{2,3}$ \\ 'The Second Clinical Medical \\ College of Zhejiang Chinese Medical \\ University, Hangzhou, Zhejiang \\ province, People's Republic of China; \\ ${ }^{2}$ Department of Thoracic Medical \\ Oncology, Zhejiang Cancer Hospital, \\ Hangzhou, People's Republic of China; \\ ${ }^{3}$ Zhejiang Key Laboratory of Diagnosis \\ \& Treatment Technology on Thoracic \\ Oncology (Lung and Esophagus), \\ Zhejiang Cancer Hospital, Hangzhou, \\ People's Republic of China
}

Correspondence: Hongyang Lu Zhejiang Key Laboratory of Diagnosis \& Treatment Technology on Thoracic Oncology (Lung and Esophagus), Zhejiang Cancer Hospital, No.I East Banshan Road, Gongshu District, Hangzhou 310022, People's Republic of China Tel +86 57I 88I2 2094

Fax +86 57I 88I 2508 Email luhy@zjcc.org.cn

\begin{abstract}
Adenosquamous carcinoma of the lung (ASC), a relatively rare subtype of non-small-cell lung cancer, is defined as a malignancy containing components of lung adenocarcinoma (ADC) and lung squamous cell carcinoma (SCC). Although ASC has biological characteristics of ADC and SCC, it is not by any means a simple hybrid of two components above. It is extremely difficult to diagnose preoperatively; pathology of surgically resected gross specimen is the most effective means for adequate diagnosis of ASC. Platinum-based postoperative adjuvant chemotherapy for at least four cycles can significantly improve the survival in stage III patients with ASC. Epidermal growth factor receptor tyrosine kinase inhibitors (EGFR-TKIs) such as erlotinib and gefitinib can be the effective therapeutic strategies for advanced EGFRmutant ASC. The studies of crizotinib in the treatment of patients with ASC are very limited. Immune checkpoint blockade therapy may be a potential treatment choice for ASC patients.
\end{abstract}

Keywords: adenosquamous carcinoma of the lung, clinicopathological characteristics, histogenesis, prognosis, chemotherapy, targeted therapy, immunotherapy

\section{Introduction}

Adenosquamous carcinoma of the lung (ASC) is a subtype of non-small-cell lung cancer (NSCLC), containing components of lung adenocarcinoma (ADC) and lung squamous cell carcinoma (SCC). Prior to 1999, the definition of ASC was a debatable point (Table 1). On one hand, although investigators reached consensus on the presence of definite components of ADC and SCC in ASCs, they disagreed over the cutoffs for the proportion of each component. The first diagnostic criterion for ASC was published in 1978 by the Japan Lung Cancer Society, which suggested that components of SCC and ADC should account for at least $20 \%$ of the tumor tissue examined using H\&E staining under the light microscope. ${ }^{1}$ In 1981, the WHO published a second edition of Histological Typing of Lung Tumors, which did not stipulate the proportion and differentiation of two components for ASCs. ${ }^{2}$ Based on these standards, in 1985, Fitzgibbons and $\mathrm{Kern}^{3}$ have suggested that in the diagnosis of a squamous component, a simple "pavementing" appearance does not suffice, that is, intracellular keratinization in the form of keratin pearl or intercellular bridges should be observed; similarly for ADC components, glandular, papillary, or tubular structures should be observed within the tumor. Nonetheless, under this rigorous classification, the incidence of ASC has shown to be only $0.6 \%(7 / 1,125)$. Conversely, another study have relied on electron microscope instead of light microscope for diagnosing ASCs. ${ }^{4}$ McDowell et al ${ }^{5}$ have reported that, based on the ultrastructural appearance, $>46 \%$ of lung carcinomas are ASCs, which further caused great disparity in the incidence of ASC. In 1999, WHO uniformed the definition of ASC as a carcinoma containing components of both SCC and $\mathrm{ADC}$, which is diagnosed when each component constitutes at least $10 \%$ of the tumor under a light microscope. This definition was published in 2015, in the fifth 
Table I Development of definition of ASC

\begin{tabular}{lll}
\hline Author & Year of publication & Main points \\
\hline The Japan Lung Cancer Society & 1978 & Components of SCC and ADC should account for at least 20\% of the tumor \\
$\mathrm{WHO}^{2}$ & $198 \mathrm{I}$ & Diagnosis of ASC can be established once components of ADC and SCC are identified \\
Fitzgibbons and Kern & 1985 & Diagnosis of components of ADC and SCC must be based on the corresponding \\
& 1999 & $\begin{array}{l}\text { typical characteristics } \\
\mathrm{WHO}^{6}\end{array}$ \\
\hline
\end{tabular}

Abbreviations: ADC, adenocarcinoma; ASC, adenosquamous carcinoma of the lung; SCC, squamous cell carcinoma.

edition of WHO Classification of Lung Cancer and is currently valid; ${ }^{6}$ nevertheless, it still causes controversies among some of the researchers. ${ }^{7}$

ASC is a malignancy with low incidence, strong aggressiveness and poor prognosis. There is no unified standard chemotherapy for ASC, and current treatment options rely on the NSCLC guidelines; surgical resection is the only effective means to cure ASC. The following review focuses on the clinicopathological characteristics, histogenesis and treatment of ASC.

\section{Clinicopathological characteristics of ASC}

ASC is a relatively rare subtype of lung carcinoma, which accounts for $0.4 \%-4 \%$ of all lung carcinomas. ${ }^{6}$ The proportion of ASC in lung carcinoma reported by different countries has no significant dissimilarities with that reported by WHO. ${ }^{8-13}$ Many studies have shown that ASC occurs more likely in men, while the proportion of patients with $\mathrm{ADC}$ and SCC varies. ${ }^{8,12-14}$ Maeda et al ${ }^{12}$ have identified 114 ASC cases in 4,668 postoperative patients with pulmonary malignancy, indicating that the ratio of male to female was 3.38:1 (ADC: 1.13:1; SCC: 10.9:1), and the average age at the time of diagnosis of ASC was higher compared to age at the diagnosis of ADC (68.7 and 65.2 years, respectively, $P<0.0001)$. Furthermore, high rates $(74.4 \%-88.5 \%)$ of smoking in patients with ASC have been confirmed by many studies. ${ }^{9}, 12,15$ Watanabe et al $^{9}$ have analyzed 52 surgically resected ASC patients and have shown a decrease in proportion of smoking among females compared to males ( $42 \%$ and $94 \%$, respectively). Interestingly, the two proportions were above the corresponding smoking rates counted among female and male patients with lung carcinoma in a larger cohort study ( $22.9 \%$ and $88.5 \%$, respectively), which included 26,957 patients with NSCLC. ${ }^{16}$ To summarize, ASC is more prevalent in older male smokers (Table 2).

Making a definite preoperative diagnosis of ASC is very difficult. Biopsy sections usually contain only ADC or SCC components because of sample limitation. Jin et $\mathrm{a}^{17}$ have retrospectively analyzed preoperative serum carcinoembryonic antigen (CEA) and SCC antigen levels in patients with lung cancer, suggesting that increased levels of CEA and SCC antigen in patients with ADC could be potential predictors of ASC. Nevertheless, pathology on surgically resected gross specimen is considered the most effective means to make an adequate diagnosis of ASC. Mordant et $\mathrm{a}^{10}$ have reviewed 141 ASC cases and have found that only three patients (2\%) were diagnosed with ASC before surgery, while more than half of the patients had no available diagnosis until operation.

According to different proportions of the two components, ASC is further subdivided into three subtypes: ADCpredominant $\mathrm{ASC}$ (the proportion of $\mathrm{ADC} \geq 60 \%$ of tumor), SCC-predominant ASC (the proportion of SCC $\geq 60 \%$ of tumor) and structure-balanced ASC (the proportion of ADC and SCC is between $40 \%$ and $60 \%){ }^{11,15}$ Zhao et a ${ }^{18}$ and Gawrychowski et a $1^{15}$ have found that structure-balanced ASC had a better prognosis compared to other types. It is generally accepted that radiographic features of ASC are non-specific in comparison with other types of lung cancer. However, some studies have shown that ASC has its own characteristics in iconography (Table 2). With regard to

Table 2 Clinical characteristics of ASC

\begin{tabular}{|c|c|}
\hline Clinical factors & Characteristics \\
\hline Morbidity & $0.4 \%-4 \%$ of all lung carcinomas ${ }^{6}$ \\
\hline Sex & Mainly males ${ }^{8,12-14}$ \\
\hline $\begin{array}{l}\text { Average age at the time } \\
\text { of diagnosis of ASC }\end{array}$ & 68.7 years $^{12}$ \\
\hline Smoking history & $\begin{array}{l}\text { Most patients with ASC have smoking } \\
\text { history } y^{9,10,12,15}\end{array}$ \\
\hline Location in CT findings & Peripheral types more than central ${ }^{9}$ \\
\hline \multicolumn{2}{|l|}{ Pathological subtype } \\
\hline \multirow[t]{2}{*}{ ADC-predominant } & Mainly peripheral located; ${ }^{9,19,20}$ peripheral \\
\hline & GGO can be a predictive marker ${ }^{21}$ \\
\hline SCC-predominant & Mainly central located ${ }^{9,19,20}$ \\
\hline Structure-balanced & $\begin{array}{l}\text { Has a better prognosis compared to } \\
\text { other types } 15,18\end{array}$ \\
\hline
\end{tabular}

Abbreviations: $A D C$, adenocarcinoma; $A S C$, adenosquamous carcinoma of the lung; CT, computed tomography; GGO, ground-glass opacity; SCC, squamous cell carcinoma. 
computed tomography (CT) findings, ASC is more likely to be manifested as peripheral than central. ${ }^{9}$ Previous studies have also indicated that central ASC squints are SCC-predominant, while peripheral ASC squints tend to be ADC-predominant. ${ }^{9,19,20}$ In a retrospective study, Lee et $\mathrm{al}^{21}$ have identified a larger central ASC compared to peripheral types $(5.7 \pm 1.2 \mathrm{~cm}$ and $3.4 \pm 1.8 \mathrm{~cm}$, respectively), while the foci with diameter $>5 \mathrm{~cm}$ were considered poor prognostic predictors. ${ }^{9}$ Furthermore, the study suggested that peripheral ground-glass opacity (GGO), as seen on CT, could be one of the predictive markers of AC-predominant ASC, especially in cases where a diagnosis of SCC with peripheral GGO is based on a biopsy specimen. CT imaging revealed that spiculate was more frequent in peripheral tumors than in central ones. ${ }^{21}$ In addition, centrally located ASCs tended to reveal inflammatory changes surrounding the foci $(P<0.005)$, which predicted a poor prognosis, and it was irrelevant to the component that was dominant in the tumor. ${ }^{9}$

\section{Histogenesis}

Histopathology and molecular pathology have verified that distinct subtypes of lung cancer have different cell origins. Classic theory presumed that ADC arises from type II alveolar epithelial cells (AT II), while SCC originates from basal cells in more proximal bronchus. ${ }^{22-24}$ However, it still remains unclear whether ASC is a simple patchwork of ADC and SCC. Many studies have shown that at the molecular level, ASC is more complex than previously assumed. Shimoji et $\mathrm{al}^{25}$ have divided 21 postoperative ASCs into four groups based on their expression of thyroid transcription factor-1 (TTF-1) and p63: TTF-1+/- and p63+/-. CEA expression was found in each ASC. Nonetheless, its staining intensity differed among distinct areas, various ADC components and a higher expression in SCC's as well as the strongest immunoreactivity present in solid carcinoma nest centers and especially necrotic parts, and thus suggesting that ASC is a heterogeneous tumor. Bastide et $\mathrm{al}^{26}$ have made transcriptomics analyses on primary rat lung carcinomas that were induced by radon progeny inhalation. In 19 lung cancer tissue specimens, five were ADCs, five were SCCs and the others were ASCs. The results showed that there were 72 differently expressed genes between ADCs and SCCs (39 genes differentiated ADCs from ASCs and 40 genes discriminated between SCCs and ASCs). Moreover, ASC tended to be a "pure" hybrid type of ADC and SCC, because ASCs were classified as intermediate between $\mathrm{ADC}$ and $\mathrm{SCC}$, since the portion of $\mathrm{ASC}$ resembled $\mathrm{ADC}$ and others were more similar to
SCC. Nonetheless, it is noteworthy that some genes with an important role in tumorigenesis were observed in ASC, including abnormal expression of genes involved in extracellular regulated protein kinases (ERK) activation pathway and neuroendocrine differentiation, which could partly explain the relatively high invasiveness ability of ASC. ${ }^{26}$ Shu et $\mathrm{al}^{27}$ have retrospectively investigated the thymidylate synthase (TS) expression by immunohistochemistry (IHC) in surgically resected ADCs $(n=121)$, SCCs $(n=17)$ and ASCs $(n=19)$ and have found that the average H-score of TS expression in ASC roughly equaled that of SCC, but significantly exceeded that of ADC. Furthermore, in ASC samples, there was no prominent difference in TS expression between squamous components and glandular components. Also, higher levels of TS expression frequently presaged poorer efficacy of pemetrexed. ${ }^{28}$ Meanwhile, Shu et al have found two mutations, ie, epidermal growth factor receptor (EGFR) mutations and six harboring kirsten rat sarcoma 2 viral oncogene homolog (KRAS) mutations, respectively, in 19 ASC specimens, with mutations present in both components. ${ }^{27}$ Similar results have also been observed by Tochigi et al. ${ }^{29}$ To sum up, based on these data, we could conclude that ASC is not a hybrid of ADC and SCC, but a cancer with more complicated histogenesis at the molecular level.

Based on histogenesis, theories related to the possible histogenic pathways of ASC can be roughly divided into three categories: bipotential undifferentiated cell origin, transitional state and "collision".

\section{Bipotential undifferentiated cell origin}

Large-scale sequencing analyses of solid tumors have confirmed that extensive heterogeneity exists in solid cancers between individual tumors, and intratumoral heterogeneity has also been identified in gene, ${ }^{30}$ including in lung cancer. Occurrence of intratumoral gene mutations of monoclonal origin can be compared to growth of the trees, which in the beginning only have trunks and then branches continue to constantly grow out. ${ }^{30}$ Driver mutations tend to be in the trunk of neoplastic evolutionary tree, whereas passenger mutations in the branch. This theory implies that ASC derives from a bipotential undifferentiated cell and then differentiates into ADC and SCC. Vassella et $\mathrm{al}^{22}$ have analyzed the mutational profile in each component among 16 Caucasian ASC samples by laser capture microdissection (LCM), fluorescence in situ hybridization (FISH) as well as next-generation sequencing (NGS). The results revealed a higher prevalence of EGFR and PI3K pathway-concerned mutations $(31.25 \%$ and $25 \%$, respectively) in contrast with classic Caucasian ADC and 
SCC, and the same EGFR mutations were contained in both components, while no KRAS mutations were observed. Moreover, this study showed centralization of drive mutations in the trunk and a high incidence of branch mutations in ASC, suggesting that ASC arose from a common precursor cell, which was in line with findings obtained in other studies, ${ }^{29,31,32}$ while the separation of ADC and SCC components may have taken place very early during the proceeding of ASC. ${ }^{22}$ According to Niho et al, ${ }^{33}$ clonal analyses have been carried out on both components of ASC tissues based on the human androgen receptor gene (HUMARA), an $\mathrm{X}$-chromosome-linked polymorphic marker. All four cases exhibited either "long pattern" or "short pattern" and each component had same monoclonal pattern, except for one in which loss of heterozygosity (LOH) in HUMARA locus was found only in SCC component. Amplification of HUMARA in SCC component did not occur after methylation-sensitive restriction enzyme HpaII digestion, indicating identical pattern to ADC component. Mather et $\mathrm{al}^{34}$ have isolated specific cancer stem-like cells (CSLC) co-expressing cytokeratin 5 and 7 (CK5, CK7) from patients with ASC and cultured them in vitro, which were then implanted in immune-deficient mice. Original ASC morphology was rebuilt, and xenograft cells expressed majority of CK5+/CK7-, CK5-/CK7+ or CK5-/CK7-, supporting a common origin of a single cell that had the potential to differentiate into either ADC-like or SCC-like carcinoma of ASC. Additionally, markers of basal cells, Clara cells, bronchial epithelial cells, pneumocytes and neuroendocrine cells were found in xenografts derived from ASC-CSLC, suggesting that the single cell may be a bi- or multi-potential lung stem cell instead of a stem cell located on the border of basal cells and alveolar epithelial cells.

\section{A transitional state between ADC and SCC}

Some studies have suggested that ASC is a transitional stage between ADC and SCC, which is not in conflict with the theory that each component of ASC is of monoclonal origin. Kanazawa et $\mathrm{al}^{35}$ have compared gene status of $\mathrm{p} 53$ and KRAS, chromosome abnormalities at 9p21 and 9q31-32, and immunohistochemical profiles between each component of 12 ASCs. Briefly, these data indicated that p53 overexpression was found in both components as well as in the transitional area of five samples with p53 immunoreactivity; also, no significant difference in $\mathrm{p} 53$ expression was found in distinct tumor areas. Moreover, chromosome abnormalities at 9p21 and 9q31-32 were coincident in both components. Interestingly, no KRAS mutations were detected in any of the tumor components, which was inconsistent with KRAS mutation frequency in classical ADC in copious reports. ${ }^{36,37}$ Besides, higher expression of SCC-related antigen and lower expression of Mucin 1 (MUC1), an antigen predominantly expressed in ADC, were found in ADC component. ${ }^{35}$ These results strongly indicated that squamous differentiation was the primary lesion in these ASCs. On the other hand, Han et $\mathrm{al}^{24}$ have observed that Lkb1-deficient ADC can progressively transdifferentiate into SCC in mouse models, suggesting that ASC is an intermediate step for the process of lung ADC to SCC. Furthermore, Tsuhako et al ${ }^{38}$ have detected human papillomavirus (HPV) in 23 surgically resected ASC samples. Under a light microscope, the cytoplasm of ADC cells adjacent to the SCC components expanded, and these larger cells revealed immunoreactivity for high molecular weight cytokeratin (HMC) and involucrin and contained HPV DNA, conjecturing ADC transiting to SCC in ASC.

\section{A collision resulted from mingling of ADC and SCC}

This viewpoint stated that ASC was the product of an "encounter" between separate independent foci of ADC and SCC. Hammond et a ${ }^{139}$ have established a lung cancer hamster model and have shown that each component appears more spatially discrete with smaller diameters and exhibits distinct biological characteristics, whereas mingling of both components is more obvious with larger diameters. Hammond et al suggested that the two components originate from different cells, respectively, but concomitantly, and collision occurs as two neoplasms encounter each other. Nevertheless, whether the observations from this study can be applied to humans remains unclear. Additionally, a case report by Kitamura et $\mathrm{al}^{40}$ of a man who had primary ADC and SCC in the right upper lobe may support this explanation.

\section{Treatment}

Surgery is the preferred treatment option for ASC patients. Lobectomy with lymphadenectomy is considered a standard treatment, while sublobar resection can be applied for early-stage lung cancers or in patients with low pulmonary function. ${ }^{41}$ Mordant et $\mathrm{al}^{10}$ have retrospectively compared postoperative ASCs with contemporaneous ADCs and SCCs; patients with ASC underwent pneumonectomy roughly as often as patients with SCC, but more frequently compared to patients with ADC; these data were in accordance with the study by Maeda et al. ${ }^{12}$ Relatively speaking, ASC has a more advanced postoperative stage and a more frequent lymph nodal invasion compared to ADCs and SCCs. ${ }^{8}$ Kong et al ${ }^{42}$ retrospectively analyzed status of lymph node metastasis in 1,156 patients with surgically resected lung cancer by IHC 
and H\&E staining. Of 49 ASCs, 26 cases were diagnosed as metastatic lymph node, and there was a higher frequency of N2 stage lymph node metastasis in ASC (40.5\%) than in ADC (18.7\%) and in SCC (21.6\%). In the study by Maeda et al, ${ }^{12}$ the 5 -year survival rate in all stage patients with ASC is $23.3 \%$, while it is $40.8 \%$ for SCC and $58.0 \%$ for ADC. Also, larger survival differences between ASC and ADC were found in earlier stages. For p-stage IA tumors, the 5-year survival rates were $42.0 \%$ for ASC, $81.8 \%$ for ADC and $63.4 \%$ for SCC; statistical difference was observed between ASC and ADC $(P=0.0005) .{ }^{12}$ Shimoji et al have shown that 3 -year recurrence-free survival rate for postoperative ASC patients is $56 \%$ and $69 \%$ in p-stage I cases. ${ }^{6}$ Furthermore, Gawrychowski et $\mathrm{al}^{15}$ have analyzed the data from 96 ASC patients revealing that the cumulative postoperative survival rates at 5 and 10 years are $25.4 \%$ and $19.2 \%$, respectively, as compared to $42.5 \%$ and $39.1 \%$ of contemporaneous ADC cases. In summary, ASC has a much more aggressive nature compared with $\mathrm{ADC}$ and $\mathrm{SCC}$, and thus early detection, diagnosis and surgery are essential for curing ASC.

Platinum-based postoperative adjuvant chemotherapy has been accepted as the standard treatment for stage II-IIIA NSCLC. ${ }^{43,44}$ A retrospective review including 2,157 lung cancer patients after surgery was carried out by Filosso et al. Stage I-II and stage III-IV patients underwent platinumbased postoperative adjuvant chemotherapy. ${ }^{8}$ The survival curve revealed a longer survival in patients receiving adjuvant chemotherapy compared to those who did not receive adjuvant chemotherapy ( $P=0.02)$, and thus adjuvant therapy was revealed to be an independent positive prognostic factor for $\mathrm{p}$-stage IA-IIIB patients with ASC. ${ }^{12}$ Feng et $\mathrm{al}^{45}$ have collected data from 181 patients with ASC and have found that platinum-based postoperative adjuvant chemotherapy significantly improved the survival in stage III patients, and there was a significant correlation between the cycles of chemotherapy and survival rates. Furthermore, 3 and 5-year survival rates for patients undergoing at least four chemotherapeutic cycles were $43.4 \%$ and $31 \%$, respectively, which was significantly higher compared to patients treated with neoadjuvant chemotherapy or 1-3 chemotherapeutic cycles. In case of a more aggressive biological behavior of ASC which in turn causes more frequent brain metastases, a postoperative prophylactic cranial irradiation might be necessary. ${ }^{8}$

Epidermal growth factor receptor tyrosine kinase inhibitors (EGFR-TKIs) can be used as first-line therapy for advanced EGFR-mutant NSCLC. ${ }^{46-49}$ As ASC is a relatively rare type of NSCLC, the data on efficacy of EGFR-TKIs for patients with ASC are limited. Wang et $\mathrm{al}^{50}$ have determined mutational status of EGFR in postoperative specimens of
ASC using PCR. Of 76 ASCs, the frequency of EGFR mutations is $31.6 \%(24 / 76)$, which is lower than that in ADC but higher than that in SCC, and it is consistent with some other studies. ${ }^{31,51}$ A significantly higher rate of EGFR mutations occurred in nonsmokers $(51.5 \%$ vs $16.3 \% ; P=0.001)$ and in tumors lager than $3 \mathrm{~cm}(41.3 \%$ vs $16.7 \% ; P=0.024) .{ }^{50}$ Song et $\mathrm{al}^{52}$ have retrospectively reviewed 49 patients with ASC, who received erlotinib or gefitinib treatment. Among these cases, stable disease (SD) was observed in 19 cases, partial response $(\mathrm{PR})$ in 13 cases, while the disease control rate was $65.3 \%$. Moreover, the median progression-free survival (PFS) and median survival time were 4.3 and 17.6 months, respectively. While comparing the data with contemporaneous cohort of SCC and ADC, statistical differences in PFS among three types were observed, ie, 4.3 months for ASC, 4.2 months for ADC and 1.9 months for SCC (all $P<0.05$ ). In addition, this study revealed higher efficacy of EGFRTKIs for EGFR-positive patients with ASC than that for EGFR-negative ones. ${ }^{52}$ Similar results are shown in another retrospective study by Fan et al, ${ }^{53}$ in which 27 EGFR-mutant patients with recurrent ASC after resection who received EGFR-TKIs treatment were enrolled. Accounted for by 9 PR and $11 \mathrm{SD}$, the disease control rate is $74.1 \%(20 / 27)$. Median PFS and median postoperative OS reach 15 and 39 months, respectively. Tamura et $\mathrm{al}^{54}$ have reported a female EGFRmutant patient with ASC, who successfully underwent a second-line rechallenge with afatinib after failure of first-line gefitinib. Another case of ASC, which acquired resistance to afatinib as a result of T790M-positive status, was reported by Ricciuti et al..$^{55}$ Detection for EGFR mutation in advanced patients with ASC should be a routine testing, and EGFR-TKI therapy for EGFR-positive ASC patients is recommended.

NSCLC patients with anaplastic lymphoma kinase (ALK) rearrangements are sensitive to ALK inhibitors. Wang et $\mathrm{al}^{50}$ reported four ALK fusions (5.3\%) in 76 patients with ASC. In a case report by Chaft et $\mathrm{al},{ }^{56}$ a male postoperative ASC patient with ALK rearrangement was first treated with chemotherapy. Recurrence was observed 2 years later, and then the crizotinib treatment was administered. Tumor continuously shrunk over 13 months, while lymph nodes remained stable. Mesenchymal-epithelial transition factor (MET) is a potential therapeutic target in NSCLC, while the significant efficacy of crizotinib for NSCLC patients with ROS protooncogene 1 (ROS1) rearrangements has been confirmed. ${ }^{57}$ In a study analyzing 16 Caucasian ASC samples by NGS, ${ }^{22}$ no MET mutation and ROS1 rearrangement were detected. Further studies are needed to determine whether ALK inhibitors may be effective for MET-mutant or ROS1 rearrangements in patients with ASC. 
Immune checkpoint blockade therapies have earned its spurs in the treatment of malignant tumors in recent years. ${ }^{58}$ Key immunological checkpoint proteins include programmed death 1 (PD-1) and its ligand PD-L1. Shi et al ${ }^{59}$ have evaluated the expression of PD-L1 in patients with ASC using IHC and in situ hybridization. The rate of $\mathrm{PD}-\mathrm{L} 1$ expression was similar in ADC components of ASC and ADC (11.1\% and $13.5 \%$, respectively), as well as the SCC components and SCC (38.89\% and 28.9\%, respectively). PD-L1 inhibitor may be a potential treatment choice for ASC patients with high PD-L1 expression; nonetheless, these observations need to be further verified by larger studies.

\section{Conclusion}

To summarize, ASC is a special subtype of NSCLC, different from ADC and SCC. Fibrobronchoscope brush biopsy, transbronchial needle aspiration biopsy (TBNA) and CT-guided biopsy are not reliable means for diagnosing ASC. Compared with $\mathrm{ADC}$ and $\mathrm{SCC}$, it has higher grade malignancy, stronger lymph nodal invasiveness, more frequent brain metastases and poorer prognosis. Even though the most effective chemotherapy regimen for patients with ASC remains unclear, platinum-based doublet chemotherapy should be considered as standard treatment option, which needs to be verified by larger studies. Detection of EGFR mutation in advanced patients with ASC should be a routine testing, and EGFRTKIs can be an effective treatment for EGFR-positive patients with ASC. Crizotinib may be a potential choice for advanced ALK-rearrangement ASC patients. Immune checkpoint blockade therapies are important issues nowadays, and it may be feasible to recommend PD-L1 testing in patients with ASC.

\section{Acknowledgment}

The present study was supported by Public Welfare Technology Application Studies Program of Zhejiang Province (No 2016C33118) and the 1022 Talent Training Program of Zhejiang Cancer Hospital.

\section{Disclosure}

The authors report no conflicts of interest in this work.

\section{References}

1. The Japan Lung Cancer Society. General Rules for Clinical and Pathological Record of Lung Cancer. 3rd ed. Tokyo: Kanehara; 1987.

2. WHO. Histological typing of lung tumors. Am J Clin Pathol. 1982;77:123.

3. Fitzgibbons PL, Kern WH. Adenosquamous carcinoma of the lung: a clinical and pathologic study of seven cases. Hum Pathol. 1985;16(5): 463-466.

4. McDowell EM, McLaughlin JS, Merenyl DK, et al. The respiratory epithelium. V. Histogenesis of lung carcinomas in the human. $J$ Natl Cancer Inst. 1978;61(2):587-606.
5. Mcdowell EM, Mclaughlin JS, Merenyl DK, Kieffer RF, Harris CC, Trump BF. The respiratory epithelium. V. Histogenesis of lung carcinomas in the human. $J$ Natl Cancer Inst. 1978;61(2):587-606.

6. Travis WD, Brambilla E, Burke AP, Marx A, Nicholson AG. WHO Classification of Tumours of the Lung, Pleura, Thymus and Heart. Lyon: International Agency for Research on Cancer; 2015.

7. Rao N. Adenosquamous carcinoma. Semin Diagn Pathol. 2014;31(4): 271-277.

8. Filosso PL, Ruffini E, Asioli S, et al. Adenosquamous lung carcinomas: a histologic subtype with poor prognosis. Lung Cancer. 2011;74(1): 25-29.

9. Watanabe Y, Tsuta K, Kusumoto M, et al. Clinicopathologic features and computed tomographic findings of 52 surgically resected adenosquamous carcinomas of the lung. Ann Thorac Surg. 2014;97(1): 245-251.

10. Mordant P, Grand B, Cazes A, et al. Adenosquamous carcinoma of the lung: surgical management, pathologic characteristics, and prognostic implications. Ann Thorac Surg. 2013;95(4):1189-1195.

11. Shimizu J, Oda M, Hayashi Y, Nonomura A, Watanabe Y. A clinicopathologic study of resected cases of adenosquamous carcinoma of the lung. Chest. 1996;109(4):989-994.

12. Maeda H, Matsumura A, Kawabata T, et al. Adenosquamous carcinoma of the lung: surgical results as compared with squamous cell and adenocarcinoma cases. Eur J Cardiothorac Surg. 2012;41(2):357-361.

13. Cooke DT, Nguyen DV, Yang Y, Chen SL, Yu C, Calhoun RF. Survival comparison of adenosquamous, squamous cell, and adenocarcinoma of the lung after lobectomy. Ann Thorac Surg. 2010;90(3):943-948.

14. Shiozawa T, Ishii G, Goto K, et al. Clinicopathological characteristics of EGFR mutated adenosquamous carcinoma of the lung. Pathol Int. 2013;63(2):77-84.

15. Gawrychowski J, Bruliński K, Malinowski E, Papla B. Prognosis and survival after radical resection of primary adenosquamous lung carcinoma. Eur J Cardiothorac Surg. 2005;27(4):686-692.

16. Kawaguchi T, Takada M, Kubo A, et al. Performance status and smoking status are independent favorable prognostic factors for survival in non-small cell lung cancer: a comprehensive analysis of 26,957 patients with NSCLC. J Thorac Oncol. 2010;5(5):620-630.

17. Jin $\mathrm{X}, \mathrm{Xu} \mathrm{X}, \mathrm{Xu} \mathrm{H}, \mathrm{Lv} \mathrm{L}, \mathrm{Lu} \mathrm{H}$. The diagnostic value of carcinoembryonic antigen and squamous cell carcinoma antigen in lung adenosquamous carcinoma. Clin Lab. 2017;63(4):801-808.

18. Zhao H, Yang H, Yao F, et al. Improved survival associated with a balanced structure between adenomatous and squamous components in patients with adenosquamous carcinoma of the lung. Eur J Surg Oncol. 2016;42(11):1699-1706.

19. Ishida T, Kaneko S, Yokoyama H, Inoue T, Sugio K, Sugimachi K. Adenosquamous carcinoma of the lung. Clinicopathologic and immunohistochemical features. Am J Clin Pathol. 1992;97(5):678-685.

20. Ashley DJ, Davies HD. Mixed glandular and squamous-cell carcinoma of the bronchus. Thorax. 1967;22(5):431-436.

21. Lee Y, Chung JH, Kim SE, Kim TJ, Lee KW. Adenosquamous carcinoma of the lung: CT, FDG PET, and clinicopathologic findings. Clin Nucl Med. 2014;39(2):107-112.

22. Vassella E, Langsch S, Dettmer MS, et al. Molecular profiling of lung adenosquamous carcinoma: hybrid or genuine type? Oncotarget. 2015;6(27):23905-23916

23. Sutherland KD, Berns A. Cell of origin of lung cancer. Mol Oncol. 2010;4(5):397-403.

24. Han X, Li F, Fang Z, et al. Transdifferentiation of lung adenocarcinoma in mice with Lkb1 deficiency to squamous cell carcinoma. Nat Commun. 2014;5:3261

25. Shimoji M, Nakajima T, Yamatani C, et al. A clinicopathological and immunohistological re-evaluation of adenosquamous carcinoma of the lung. Pathol Int. 2011;61(12):717-722.

26. Bastide K, Ugolin N, Levalois C, Bernaudin JF, Chevillard S. Are adenosquamous lung carcinomas a simple mix of adenocarcinomas and squamous cell carcinomas, or more complex at the molecular level? Lung Cancer. 2010;68(1):1-9. 
27. Shu C, Cheng H, Wang A, et al. Thymidylate synthase expression and molecular alterations in adenosquamous carcinoma of the lung. Mod Pathol. 2013;26(2):239-246.

28. Ozasa H, Oguri T, Uemura T, et al. Significance of thymidylate synthase for resistance to pemetrexed in lung cancer. Cancer Sci. 2010; 101(1):161-166

29. Tochigi N, Dacic S, Nikiforova M, Cieply KM, Yousem SA. Adenosquamous carcinoma of the lung: a microdissection study of KRAS and EGFR mutational and amplification status in a western patient population. Am J Clin Pathol. 2011;135(5):783-789.

30. Gerlinger M, Rowan AJ, Horswell S, et al. Intratumor heterogeneity and branched evolution revealed by multiregion sequencing. $N$ Engl J Med. 2012;366(10):883-892.

31. Kang SM, Kang HJ, Shin JH, et al. Identical epidermal growth factor receptor mutations in adenocarcinomatous and squamous cell carcinomatous components of adenosquamous carcinoma of the lung. Cancer. 2007;109(3):581-587.

32. Toyooka S, Yatabe Y, Tokumo M, et al. Mutations of epidermal growth factor receptor and K-ras genes in adenosquamous carcinoma of the lung. Int J Cancer. 2006;118(6):1588-1590.

33. Niho S, Yokose T, Kodama T, Nishiwaki Y, Mukai K. Clonal analysis of adenosquamous carcinoma of the lung. Jpn J Cancer Res. 1999; 90(11):1244-1247.

34. Mather JP, Roberts PE, Pan Z, et al. Isolation of cancer stem like cells from human adenosquamous carcinoma of the lung supports a monoclonal origin from a multipotential tissue stem cell. PLoS One. 2013;8(12):e79456.

35. Kanazawa H, Ebina M, Ino-Oka N, et al. Transition from squamous cell carcinoma to adenocarcinoma in adenosquamous carcinoma of the lung. Am J Pathol. 2000;156(4):1289-1298.

36. Rodenhuis S, van de Wetering ML, Mooi WJ, Evers SG, van Zandwijk N, Bos JL. Mutational activation of the K-ras oncogene. A possible pathogenetic factor in adenocarcinoma of the lung. $N$ Engl J Med. 1987; 317(15):929-935.

37. Suzuki Y, Orita M, Shiraishi M, Hayashi K, Sekiya T. Detection of ras gene mutations in human lung cancers by single-strand conformation polymorphism analysis of polymerase chain reaction products. Oncogene. 1990;5(7):1037-1043.

38. Tsuhako K, Nakazato I, Hirayasu T, Sunakawa H, Iwamasa T. Human papillomavirus DNA in adenosquamous carcinoma of the lung. J Clin Pathol. 1998;51(10):741-749.

39. Hammond WG, Tesluk H, Benfield JR. Histogenesis of adenosquamous bronchogenic carcinoma. Cancer Lett. 1995;96(2):163-168.

40. Kitamura K, Mitsudomi T, Ishida T, Kaneko S, Sugimachi K. Adenocarcinoma and squamous cell carcinoma in the same lobe of the lung A case report. Respiration. 1991;58(3-4):226-228.

41. Schneider BJ, Daly ME, Kennedy EB. Stereotactic body radiotherapy for early-stage non-small-cell lung cancer: American Society of Clinical Oncology Endorsement of the American Society for Radiation Oncology Evidence-Based Guideline. J Clin Oncol. 2017;36(7):710-719.

42. Kong M, Jin J, Cai X, et al. Characteristics of lymph node metastasis in resected adenosquamous lung cancer. Medicine. 2017;96(48):e8870.

43. Kris MG, Gaspar LE, Chaft JE, et al. Adjuvant systemic therapy and adjuvant radiation therapy for stage I to IIIA completely resected non-small-cell lung cancers: American Society of Clinical Oncology/ Cancer Care Ontario Clinical Practice Guideline Update. J Clin Oncol. 2017;35(25):2960-2974.

OncoTargets and Therapy

\section{Publish your work in this journal}

OncoTargets and Therapy is an international, peer-reviewed, open access journal focusing on the pathological basis of all cancers, potential targets for therapy and treatment protocols employed to improve the management of cancer patients. The journal also focuses on the impact of management programs and new therapeutic agents and protocols on
44. Ettinger DS, Wood DE, Akerley W, et al. NCCN guidelines insights: non-small cell lung cancer, version 4.2016. J Natl Compr Canc Netw. 2016;14(3):255-264.

45. Feng ZX, Pang QS, Ji K. Analysis of the prognostic factors in resection of 181 patients with adenosquamous lung carcinoma. Zhongguo Zhongliu Lin Chuang. 2012;39:1656-1659.

46. Mitsudomi T, Yatabe Y. Mutations of the epidermal growth factor receptor gene and related genes as determinants of epidermal growth factor receptor tyrosine kinase inhibitors sensitivity in lung cancer. Cancer Sci. 2007;98(12):1817-1824.

47. Mitsudomi T, Morita S, Yatabe Y, et al. Gefitinib versus cisplatin plus docetaxel in patients with non-small-cell lung cancer harbouring mutations of the epidermal growth factor receptor (WJTOG3405): an open label, randomised phase 3 trial. Lancet Oncol. 2010;11(2):121-128.

48. Rosell R, Carcereny E, Gervais R, et al. Erlotinib versus standard chemotherapy as first-line treatment for European patients with advanced EGFR mutation-positive non-small-cell lung cancer (EURTAC): a multicentre, open-label, randomised phase 3 trial. Lancet Oncol. 2012; 13(3):239-246.

49. Zhou C, Wu YL, Chen G, et al. Erlotinib versus chemotherapy as first-line treatment for patients with advanced EGFR mutation-positive non-small-cell lung cancer (OPTIMAL, CTONG-0802): a multicentre, open-label, randomised, phase 3 study. Lancet Oncol. 2011;12(8): 735-742.

50. Wang R, Pan Y, Li C, et al. Analysis of major known driver mutations and prognosis in resected adenosquamous lung carcinomas. $J$ Thorac Oncol. 2014;9(6):760-768.

51. Jia XL, Chen G. EGFR and KRAS mutations in Chinese patients with adenosquamous carcinoma of the lung. Lung Cancer. 2011; 74(3):396-400.

52. Song Z, Lin B, Shao L, Zhang Y. Therapeutic efficacy of gefitinib and erlotinib in patients with advanced lung adenosquamous carcinoma. J Chin Med Assoc. 2013;76(9):481-485.

53. Fan L, Yang H, Yao F, et al. Clinical outcomes of epidermal growth factor receptor tyrosine kinase inhibitors in recurrent adenosquamous carcinoma of the lung after resection. Onco Targets Ther. 2017;10: 239-245.

54. Tamura T, Kagohashi K, Satoh H. Successful afatinib therapy after resistance to EGFR-TKI in a patient with advanced adenosquamous cell lung cancer. Oncol Res Treat. 2015;38(6):316-317.

55. Ricciuti B, Metro G, Brambilla M, et al. Acquired resistance to afatinib due to T790M-positive squamous progression in EGFR-mutant adenosquamous lung carcinoma. J Thorac Oncol. 2018;13(1):e9-e12.

56. Chaft JE, Rekhtman N, Ladanyi M, Riely GJ. ALK-rearranged lung cancer: adenosquamous lung cancer masquerading as pure squamous carcinoma. J Thorac Oncol. 2012;7(4):768-769.

57. Shaw AT, Ou SH, Bang YJ, et al. Crizotinib in ROS1-rearranged nonsmall-cell lung cancer. N Engl J Med. 2014;371(21):1963-1971.

58. Gandhi L, Rodríguez-Abreu D, Gadgeel S, et al. Pembrolizumab plus chemotherapy in metastatic non-small-cell lung cancer. $N$ Engl J Med. 2018;378(22):2078-2092.

59. Shi X, Wu S, Sun J, Liu Y, Zeng X, Liang Z. PD-L1 expression in lung adenosquamous carcinomas compared with the more common variants of non-small cell lung cancer. Sci Rep. 2017;7:46209.

patient perspectives such as quality of life, adherence and satisfaction The manuscript management system is completely online and includes a very quick and fair peer-review system, which is all easy to use. Visit http://www.dovepress.com/testimonials.php to read real quotes from published authors. 